\title{
Using Design Research for Studies on ICT in Classrooms
}

\author{
Hyeran Park \\ Ontario Institute for Studies in Education University of Toronto \\ Zuochen Zhang \\ University of Windsor
}

\begin{abstract}
In recent years, as Information and Communication Technologies (ICT) are more and more widely used in classrooms, researchers have been trying to identify effective ways for ICT to be utilized in school classrooms to enhance teaching and learning. However, it is argued that traditional scientific research methodologies are not really applicable for studies on ICT integration in classrooms, as these research approaches, more often than not, fail to reflect the dynamics and complexity of the school classroom. To meet the needs of the current situation, some researchers advocate the use of design research as an alternative methodology. Based on a review of literature, this paper first examines the advantages and problems of adopting ICT in classrooms, and then discusses the use of design research as an alternative methodology for studies on ICT in classrooms.
\end{abstract}

Since new Information and Communication Technologies (ICT), especially personal computers, were introduced to K-12 classrooms about two decades ago, comprehensive research has been conducted on their impact on teaching and learning. Empirical studies on ICT integration in classrooms address such advantages as ease of differentiating instructions (Park, Khan, \& Petrina, 2009), promotion of constructivism in teaching and learning (Bereiter \& Scardamalia, 1996; Kelly \& Tangney, 2006), and improvement of high level thinking (Diehl, Ranney, \& Schank, 2001; Scardamalia, 2002). Other studies, however, have reported insignificant effects on students' test scores (Angrist \& Lavy, 2002), lack of teachers' technological pedagogical content knowledge (Feistrizer, 1999), narrowly-used technology in classrooms for drill and practice, word processing, and the Internet surfing (Anderson \& Ronnkvist, 1999), and lack of proper software (Kenny, 2003). Particularly, narrowly-used technology has not been shown to enhance the qualitative learning process (Dede, 1999). Meta analysis reports on this topic also show these counter-effects of technology (Kulik, 1994; Sivin-Kachala, 1998). Meanwhile, studies on the influence of instructional technology are questionable because they often reflect the researchers' interests rather than issues and problems of classroom practice (Gordon \& Zemke, 2000; Reeves, 1995, 2000). Reeves (2000) criticizes instructional technology research as "research that neither seeks fundamental understanding nor considers use" (p. 3) because of its poor connections to existing research or theory, inappropriate 
application of methods, and findings that fail to inform practice. Such research, according to Reeves, is only intended to keep researchers' names on publication records so as to maintain their positions in academic institutions.

The problem, however, does not lie in the researchers. Rather, the methodology the researchers employed has been criticised (Brown, 1992; Collins, 1992; Collins, Joseph, Bielaczyc, 2004). The traditional scientific research, which most researchers have employed, has put too much emphasis on potential for empirical testing and generalization. It is mostly conducted in laboratory settings; that is, one factor is isolated as an independent variable, others are fixed, and then a researcher measures the effect of the factor. In the laboratory setting, the researcher endeavours to avoid contaminating factors and assumes that a fixed factor does not interact with other elements of teaching and learning activities. This setting does not reflect the dynamics and the complexity of the classroom (Bereiter, 2002; Brown; Collins, 1999; Cronbach, 1957, as cited in Bereiter). Brown and Collins (1992) suggest that design research could be a new paradigm for innovation in classroom research. The researcher who uses design research actively interacts and iteratively intervenes with practitioners to overcome shortcomings of initial research plans and theories and to refine the theories entailed in the learning environments.

This paper examines the advantages and problems of adopting ICT in classrooms, and explains why design research is an appropriate methodology to investigate the use of ICT. A literature review demonstrates the great potential of ICT as an instructional tool, and provides the rationale for a paradigm shift in educational research from the traditional experimental setting to design research. Some suggestions are provided for improving design research, so it can be accepted as an authentic research methodology. The ensuing discussion intends to present post positivistic perspectives on design research, which could accredit it as a scientific research methodology.

\section{The Advantages and Problems of ICT in K-12 Classrooms}

Many studies support the effectiveness of technology for enhancing students' understanding of academic knowledge (Culp, Honey, \& Mandinach, 2005; Roschelle, Pea, Hoadley, Gordin \& Means, 2000), for expanding the scope and the depth of teachers' teaching (Becker, 2000; Culp el al., 2005), for supporting inquiry, collaboration, or re-configured relationships among students and teachers (Becker, 2000), and for encouraging students to engage actively in their learning (Butler \& MacGregor, 2003; Williams, Chen \& Seaton, 2003). Educational literature has also shown the possibility of using ICT as a bridge over the gaps between schools and societies (Butler \& MacGregor, 2003), and between higher and lower achievement groups (Kozma \& Wanger, 2006; Linn, 1992; Smeets, 2005; Park et al., 2009; White \& Frederiksen, 1998). Moreover, the ability to use and to invent advanced technology is a central factor in globalized economic competitiveness; thus, technology literacy is a crucial element for students' future careers (Becker; Culp et al; Hargreaves, 2003).

Although most teachers use computers in their classrooms, their use is limited to presentation software such as PowerPoint, word processing programs and surfing Internet resources (Becker, 2000; Culp et al., 2005). Fishman, Marx, Blumenfeld, Krajcik, and Soloway (2004) point out that cognitively-oriented 
technology innovations, which are believed to foster thinking and deep understanding in science, are not widely used in schools. Reasons for this poor level of adoption include the lack of teachers' technological pedagogical knowledge (Fishman et al., 2004; Koehler \& Mishra, 2005), the lack of infrastructure (Fishman et al.; Roschelle \& Pea, 1999), the lack of available guidance for teachers to keep up with fast changes in ICT, and the overflow of too much irrelevant information (Negroponte, Resnick \& Cassel, 1997; Rochelle \& Pea; November, 2002). Moreover, the systemic complexities of school organization, curriculum, family conditions and digital gaps among participants are major challenges for researchers (Fishman et al.). In addition to the "digital divide," teachers' misunderstanding of integrating technology in class (Earle, 2002) is also a challenge. According to Earle, teachers assume that integrating technology is a matter of mastering specific software products rather than mastering the content of a subject domain. He argues that "Technology involves the tools with which we deliver content and implement practices in better ways. Its focus must be on curriculum and learning. Integration is defined not by the amount or type of technology used, but by how and why it is used" (p. 8). Envisioning the great potential of instructional technology, researchers suggest various solutions on how to improve the adoption of ICT, including: encouraging teachers' active participation and socio-cognitive scaffolding (Roschelle \& Pea), systemic reform (Fishman et al.), improving accessibility, solid infrastructure, generation of valuable information (Culp et al., 2005; Earle; Roschelle \& Pea) and providing high quality professional development for teachers (Culp et al.). Unfortunately, such research suggestions do not fully reflect real classroom situations; thus they are not easy to be fully implemented in K-12 classrooms. Once a research study is concluded, the applicability and sustainability of the methods are not pursued (Fishman et al.). The major reason for this disconnection of research from real practice is that most research endeavours to focus on one or two factors and to isolate a classroom from other influencing elements (Cobb, Confrey, diSessa, Lehrer, \& Schauble, 2003; Collins et al., 2004).

Various suggestions have been given on how to improve the adaptation of ICT, including: encouraging teachers' active participation and socio cognitive scaffolding (Roschelle \& Pea, 1999), systemic reform (Fishman et al., 2004), improved accessibility, solid infrastructure, generation of valuable information (Culp et al., 2005; Roschelle \& Pea) and providing high quality professional development for teachers (Culp et al.). Such research suggestions, however, are not easy to fully implement in K-12 classrooms.

Some cognitive science researchers like Brown (1992) and Collins (1992, 1999) suggest the need of a new paradigm different from experimental research methodologies. The new methodology, design research, takes into account the complexity of human society and makes active, flexible and iterative interventions in order that the research findings may lead to practical innovation in teaching and learning environments. Bereiter (2002) points out that the reason for the failure of classroom innovations lies in the complexity of human society rather than any resistance to change in the educational system or in the psychological makeup of teachers. Shepard's remarks at AERA 2000 (as cited in 
Fishman et al., 2004) stress that researchers should develop methodologies to solve practical problems in real-world settings.

\section{Traditional Experimental Research vs. Design Experiments}

As documented in the literature, classroom ICT have immense potential to improve teaching and learning at different grade levels. However, many have sceptical views of educational technology research (Gordon \& Zemke, 2000; Reeves, 2000) because of the "lack of linkage to theoretical foundations, inadequate literature reviews, poor treatment implementation, major measurement flaws, inconsequential learning outcomes for research participants, inadequate sample sizes, inaccurate statistical analyses, and meaningless discussions of results" (Reeves, p. 4). Lagrange, Artigue, Labord and Trouche (2001) conducted a meta-analysis of over 600 studies on ICT in education and reported that research has difficulties in the complex integration of evolving technologies with real situations.

An examination of previous methodologies may help discover alternatives to technology-mediated educational research. Many empirical studies on educational technology have been conducted with experimentally or quasiexperimentally designed and strictly controlled methods in a laboratory situation (Gordon \& Zemke, 2000; Reeves, 1995; 2000). Such experimentally designed research is suitable for the complicated physical world, in which one variable can be changed while others are fixed (Bereiter, 2002; Davis, Sumara, Luce-Kepler, 2000). The research context is isolated to avoid the impacts of extraneous factors and to measure specific variables. The over-all goal of this hypothesis-testing research is to develop long-lasting, widely applicable theories and unambiguous principles that can be used to guide practitioners for implementation. Experimental research is very successful in natural science, where findings can generate a universal statement (theory) on which scientists can be enabled to predict what will happen if a factor changes.

Such experimental research methodologies (based on positivistic premises ) (Boyd, 2002; Chalmers, 1999; Hickey, 2005) have significantly affected the fields of psychology, education, social science and economy research on the assumption that the research context is the same as the physical world (Bechtel, 1988; Bereiter, 2002; Davis et al., 2000). In education, behaviourists and cognitivists regard learning as acquiring established knowledge, and researchers belonging to this category emphasize objectivity, minimize researchers' engagement, and measure how much students acquire (understand) knowledge or how differently students behave when a variable is manipulated (Good \& Brophy, 1990; Sfard, 1998). Rejecting constructivist epistemology, experimental researchers view knowledge as "out there" and attempt to find trans-cultural commonalities (Bereiter; Matthews, 1994; Siegel, 2002).

Criticisms (Brown, 1992; Collins, 1992; Collins, et al., 2004; O’Donnell, 2004) have been made about the artificial and narrow context of traditional experimental research in settings alien to real teaching and learning environments. In 1955, Cronbach (as cited in Breiter, 2002) has also pointed out that the traditional research focusing on correlation or causal effect outcomes can neither generate nor lend support to innovation in a complex world. In addition, experimental research treats a single variable, mostly how a student, a teacher, or 
a school is behaving without considering subjective dispositions (Collins et al.). In the complexity of normal classrooms, a researcher should not assume that the implemented treatment variable yields the results of his/her study while all other variables are completely immune to change. Any one change may involve interactions with other variables which also create change. Thus, the results from measuring one variable may not in fact be solely the effect of that variable.

With the human social complexity of classrooms in mind, Brown (1992) and Collins (1992) have introduced design research to offset the weakness of traditional experimental educational research. According to Collins et al. (2004), the primary goal of design research is "refining both theory and practice...by investigat[ing] how different learning environment designs affect dependent variables in teaching and learning" (p. 17, 19). It involves messy situations that are difficult to characterize, and the effectiveness of a design in one system does not guarantee its effectiveness in other systems. They define design research as a methodology in which researchers use multiple influencing variables as well as multiple outcomes in an attempt to characterize individual situations. In addition, it is an approach of progressive refinement derived from the previous research ( $\mathrm{p}$. 18). This implies that rather than using one-time research to establish a universally applicable statement, the design is constantly revised and evolved by experiences and iterative studies.

Design research has strengths for testing and refining theories as it works with practitioners, confronts everyday classroom problems and captures potential advantages by iteratively adapting and sharpening theories in the practical research context (Collins, 1999; Collins et al., 2004; Shavelson, Philips, Towne, \& Feuer, 2003). Research practice within communities (Bereiter, 2002) or localized contexts (Cobb et al., 2003) is markedly innovative, responsive to evidence, connected to basic science, and dedicated to continual improvement. Since it targets a domain-specific learning process, the findings from design research involve greater "understanding of a learning ecology - a complex, interacting system involving multiple elements of different types and levels - by designing its elements and by anticipating how these elements function together to support learning" (Cobb et al., 2003, p. 9).

Since design research is a relatively new method in educational technology research, it does have its shortcomings. It is seen to be under-conceptualized and to lack an adequate theoretical basis (Kelly, 2003; O'Donnell, 2004), It makes heavy time demands on students, teachers and researchers because of its iterative interventions (Brown, 1992; Collins et al., 2004; O'Donnell). Its small sample sizes create problems in making generalizations (O'Donnell). Despite these drawbacks, design research plays a role as a developmental tool in technologyembodied educational research together with the constructivist paradigm that learners construct their own knowledge rather than receiving or acquiring knowledge from teachers. For instance, it has been adopted as a proper methodology for many cognitively-oriented technology innovations (Fishman et al., 2004; Reeves, 2000), for knowledge building approaches (Ow \& Tan, 2006; Nason \& Woodruff, 2004) and for the assessment of e-learning for complex thinking (Botha, Westhuizen \& Swardt, 2005). Fishman et al. (2004) stress that design research has improved understanding of the constraints and the contexts for the classroom learning of ICT. For more detailed reasons to adopt design 
research for ICT in K-12 classroom innovations, this inferential explanation will be accompanied with analysis of the particular project which employs design research.

The next section will demonstrate how design research is appropriate through individual examples. Following the analysis of each example, a few suggestions are provided to researchers for adopting design research.

\section{The Advantages of Design Research for Adopting ICT in Classrooms}

Fishman et al.'s (2004) study of cognitively-oriented technology innovation, used design experiment in which "researchers work closely with teachers and students to design, develop, implement, and evaluate an innovation in real classroom settings" (p. 6) and observed the substantial influence of contextual variables in shaping systemic reform which was sustainable at various scales. Shavelson et al. (2003) assert that group work involving researchers and teachers in design research has the benefit of producing a concrete product such as a curriculum or instructional unit. Moreover, pragmatic design experiments highlight everyday classroom conditions and school problems that influence teaching, learning and adapting instruction (Cobb et al., 2003; Kelly \& Lesh, 2000; Shavelson et al.).

One of the advantages of design experiment is its flexibility and iterative intervention. According to Vygotsky (1978), learning occurs within one's Zone of Proximal Development (ZPD); successful instruction requires the process of identifying each learner's ZPD and providing learners with enough opportunities to construct their knowledge according to his/her own understandable levels (Lehtelä, 2001). As students' ZPD is not fixed, it may be gradually improved in the initial, the middle and the last stages of an intervention. Teachers and researchers need to adjust their research plans and ICT resources to dovetail both students' general development and also individual developmental differences. Iterative interventions make it possible to identify individual students' ZPDs. A flexible research plan can make adjustments for students' actual ZPDs. Ow and Tan (2006) implemented a Knowledge Forum in an elementary school science class with forty students in Singapore and tested the effectiveness of the Knowledge Building approaches (Bereiter \& Scadamalia, 2003; Bereiter, Scadamalia, Casells, \& Hewitt, 1997). The research employed design experiment with mixed methods that included three phases. Teachers and researchers continuously checked not only students' interactions among groups but also their individual understanding of scientific concepts. Based on the results of the first phase, the researchers could learn the students' ZPD and adjust their second phase. In short, the research involved tightly linked design-analysis-redesign cycles and led to positive effects on the students' learning. Some critics put the results of the design research down to the "Hawthorne effect," but as Brown (1992) argued, learners need to take ownership of their learning and the effects of intervention can be predicted by the researchers.

The close interaction and collaboration between researcher and practitioner helps cope with unexpected situations most likely to occur when ICT are adopted in the human complexity of the classroom. In Woodruff and Ninula's (2005) study, the researcher and the teacher worked together to improve Grade 2 students' literacy using handhelds. At the beginning of the research, the teacher was not sure of the students' ability to use a handheld or of the handheld's 
potential to improve student literacy. The researcher provided instruction on how to use the handheld and offered on-going technological support during the research. Thus, the teacher felt comfortable using the technology in the research. The collaboration between the researcher and the teacher helped to overcome the teacher's doubts over the results of the research. Even when the teacher was absent during research, the researcher could work with the participants. Comprehensive research identified the teacher's lack of technological pedagogical literacy. Design research, which encourages teachers' and researchers' active collaboration and also researchers' intervention, has demonstrated its usefulness when teachers are nervous about the use of ICT in classroom.

Design experiments consider several independent variables. When a study employs ICT as a way of intervention, the ICT devices can be distributed to each student. In case there are not enough devices for every student, then a number of students can share them. An ICT program may affect students' learning or attitudes, but the interactions between students and the tool, and the interactions among group members are also the elements which influence the results of research. By examining several variables, design research can be a productive means of ICT research. Ow and Tan's study (2006) viewed their Knowledge Forum as one independent variable and its different interactions as other important variables. These interactions were analyzed based on Activity theory (Kaptelinin \& Nardi, 2006). This analysis identified conflicts which were not helpful for learning. If the researchers had considered only one variable, such as the Knowledge Forum, and analyzed the data, the findings would probably have led to very biased conclusions.

Design research focuses on the research process and is utility-oriented "with the intent of improving the effectiveness of instruction tools to support learning" (Shavelson et al., 2003, p. 26). An exploratory study for introducing new tools in education emphasizes the trajectory of the research processes. The trajectory pursues both individual students' learning by understanding successive patterns in the reasoning and thinking, and the impact of instructional artefacts on that reasoning and learning. When portable computers as new tools are employed to enhance students' learning context (Squire \& Klopfer, 2007; Woodruff \& Ninula, 2005), the researchers work to learn not only the outcomes of students' learning but also the process by which students are working with the tools. They also try to establish how useful and sustainable the new tools are, and on what scale. For the purpose of research, especially introducing new tools in K-12 classrooms, design research, which is utility-driven and emphasizes the process, can be a proper method.

Design research involves researchers and practitioners co-constructing knowledge (Cobb et al., 2003; Shavelson et al., 2003). Based on the premise of collective cognitive responsibility, researchers using design research involve teachers and students, sharing responsibility with them for knowledge generation. This means that in knowledge production "the responsibility for the success of a group effort is distributed across all the members rather than being centered in the leader" (Scardamalia, 2002, p. 2). A study conducted by Nason and Woodruff (2004) shows the possibility of collective cognitive responsibility with students using Excel software on a Knowledge Forum. Students examined the validity of 
ranking countries' performance by the number of medals won at the Olympic Games. During the research, the students' activities followed a Knowledge Building approach similar to what working scientists do in their own community to generate knowledge (Bereiter et al., 1997; Scadamalia). As the procedural cycles developed from the initial model building to discussion, iterative online criticism, model revision, and problem redefinition, the results gradually became more reasonable and understandable. It is believed that findings using design research, especially with its knowledge-building and ideas-centred instruction models, are less biased; therefore, more powerful knowledge can be generated. When ICT are adopted, these models helpfully demonstrate collective cognitive responsibility.

Through these successful examples of instructional technology research, we can summarize what the studies yield and derive suggestions on how to apply design research. First, and most important of these suggestions, is that researchers must identify the nature of research situations through close interaction with teachers and students. The physical conditions of schools, classes, individual teachers and students as well as the subject area to apply ICTs are unique. To achieve useful concrete results (e.g., curriculum) and for research effects to be sustainable after studies conclude, researchers need to identify the research context. Collins et al. (2004) emphasize that research contexts are messy. Consequently, researchers need to learn how to implement ICT effectively within the mess rather than ignoring it and seeking to remove "contaminating" factors. Borrowing a computer term, mess is the "default setting" for research. The protocol for effective ICT implementation is engaging actively with the environment instead of maintaining a distance to get objectivity.

A second suggestion is that researchers need to be flexible. That is, researchers can change the initial plans or software and adjust them considering students' digital skills and conditions of research context. Mastering a software program is not the goal. It is more important to understand the content and apply the learned knowledge to a new context (Earle, 2002). By adjusting the technical difficulties and challenging their cognitive development, students can be motivated to engage actively in their learning so that they finally gain a feeling of ownership in their learning. Brown (1992) suggests that researchers should not treat this as the Hawthorn effect, but call it learners' ownership.

Third, researchers need to program instructional software to record students' activities automatically. The usefulness and benefits of automatically recorded data cannot be overlooked. These records indicate the ways students respond to a program and how students interact with technologies, thereby revealing metacognitive processes in problem solving or cognitive development. For instance, based on how students misunderstand or correct their answers to a question, researchers can find patterns in their approaches to solving problems so as to form a "proto-theory" (Design Research Collective Team, 2003, p.5). In addition, records can help to identify what teachers or researchers miss. They can be used to enhance the credibility of research findings and provide clues for revisions.

The authentic settings (Design Research Collective Team, 2003) for design research can help to build a bridge between a classroom and the real world The authenticity of a program and its findings can provide a basis for future research on instructional technology. 


\section{Discussion}

Rapid changes of ICT tools are making a significant impact on educational environments. At the same time they are consequently frustrating practitioners and even university-based researchers. Teachers with limited opportunity to catch up with these changes need practical help. Design research is a versatile approach to adopting technology in messy teaching and learning environments because its iterative practices and applications of new trials seek to meet the needs of actual research contexts. For these attempts to be successful, researchers need to be non-judgmental, empathetic and fully committed to collaboration with practitioners and to systematic reform, identifying problems and guiding problem-solving. Making technology useful and sustainable in K-12 classrooms is the joint responsibility of both teachers and researchers.

Given the complexity of participants and situations involved in educational research, different methodologies have been explored and employed. However, traditional scientific research, based on positivistic epistemology (Bechtel, 1988; Hempel \& Oppenheim 1948), is still believed to be the legitimate means to generate knowledge as it uses objective observation and experiment to obtain approximate truth (Chalmers, 1999; Goodfrey-Smith, 2003). Therefore, researchers are more often than not asked to change their methods from qualitative designs (including design research) to experimental or quasiexperimental designs, which are perceived to be more reliable, in order to get funding support (Reeves, 2003; Schrum \& Glassett, 2006). However, unlike physical science, the evidence in a study on teaching and learning does not guarantee that the research method is legitimate or scientific. Traditional experimental or quasi-experimental research may have been good enough for Popper's (1963) World 1 or World 2, but may not be so for World 3. In explaining and understanding World 3, especially when mediated by rapidly changing and advancing technologies which influence the research context, it is not enough just to measure one implementation effect and to observe action-andreactions.

Thagard's (1978) demarcation standards for science and pseudoscience can be used to address the concerns on design research as lack of scientific components (i.e., objectivity, replicability). He asserts that to make a research method legitimate, the researcher must strive to improve on weaknesses and to solve problems in the domain. He observes that a theory or a method:

has been less progressive than alternative [ones] over a long period of time, and faces many unsolved problems; but the community of practitioners makes little attempt to develop the theory towards solutions of the problems, shows not concern for attempts to evaluate the theory in relation to others, and is selective in considering confirmations and disconfirmations. (p. 32)

Kuhn's (1970) claim of demarcation of science over other disciplines also goes to show that design research can be a legitimate research method. According to him, scientific theories make predictions that may turn out to be false, but what makes science special is that it can learn from its false predictions. Implementing a method in a certain context may not match well, and then 
changing its method to maximize the learning effect is what natural scientists do in their research. Design research can be a legitimate tool when researchers using it act progressively and vigorously to tailor their methods to the research context (Brown, 1992; Collins et al., 2004).

Well- developed computer software packages such as statistical package for the social sciences (SPSS), statistical analysis system (SAS) and analysis of moment structures (AMOUS) for quantitative data analysis and ATLAS-ti and NVivo for qualitative data analysis can reduce the workload of a researcher and provide objectivity in data selection. These sophisticated data analysis software programs can also assist researchers in finding patterns and models for the generalization of research findings. Without the potential to generalize over diverse contexts, the findings of design research can become a mere collection of cases. We should admit the idiosyncrasy of each case, but if researchers overemphasize individuality, no case can be falsified at all. Thus, to be accepted firmly as a legitimate research methodology, design research needs to seek objectivity in its research findings.

In order to engage in a genuine scientific process, analytical and constructive abilities are required (Jungwirth, 1970). That is, researchers need analytical ability to comprehend scientific literature, to discern problems, to manipulate given data, to judge the relevancy and adequacy of experimental procedures and to draw proper conclusions from data. This constructive ability is necessary for a qualified researcher to formulate relevant assumptions and hypotheses to test the hypotheses including experimental conditions and replications, and to derive reliable findings from their messy research data. Successful practitioners also need to know which research findings are unique to their idiosyncratic environments and which are transferable from the research context to their own situation. These natural recursive procedures - research into practice, and practice into research - validate the development of design research as a legitimate methodology.

\section{Concluding Remarks}

Considering the complex situations in K-12 classrooms, this paper has reviewed the possibility of using design research as an appropriate methodology for ICT research. In such projects, researchers collaborate with practitioners. They use active and iterative interventions and share responsibility for knowledge generation. Design research has been criticized as under-conceptualized, overmethodologized (Dede, 2004; Kelly, 2003), and data-reductive (Brown, 1992; Collins et al., 2004; Gorard, Roberts, \& Taylor, 2004). Design research has been used in various fields for decades (Lunenfeld, 2003), but the use of it in the domain of ICT in classrooms is comparatively recent. Researchers who use this method for classroom projects on ICT need to keep improving their procedures and analysis for design research to become more widely accepted in the community.

\section{References}

Anderson, R. E., \& Ronnkvist, A. (1999, April). The presence of computers in American schools. Paper presented at 1999 meeting of the American Educational Research Association, Montreal, Canada. 
Angrist, J., \& Lavy, V. (2002). New evidence on classroom computer and pupil learning. The Economic Journal, 112 (October). 73-765.

Bechtel, W. (1988). Philosophy of science. Hillsdale, NJ: Erlbaum.

Becker, H. J. (2000). Findings from the teaching, learning, and computing survey: Is Larry Cuban right? Education Policy Analysis Archives, 8(51). Retrieved June 14, 2002, from http://epaa.asu.edu/epaa/v8n51/

Bereiter, C. (2002). Design research for sustained innovation. Cognitive Studies, Bulletin of the Japanese Cognitive Science Society, 9(3), 321-327.

Bereiter, C., \& Scardamalia, M. (1996). Rethinking learning. In D.R. Olson, \& N. Torrance (Eds.), The Handbook of education and human development: New models of learning, teaching and schooling (pp. 485-513). Cambridge, MA: Basil Blackwell.

Bereiter, C., \& Scardamalia, M. (2003). Learning to work creatively with knowledge. InE. D. Corte, L. Verschaffel, N. Entwistle, \& J. V. Merriënboer (Eds.), Powerful learning environments: Unravelling basic components and dimensions (pp. 73-78). Oxford: Elsevier Science.

Bereiter, C., Scardamalia, M., Cassells, C., \& Hewitt, J. (1997). Postmodernism, knowledge building, and elementary science. Elementary School Journal. 97(4), 329-340.

Botha, J., Westhuizen, D., \& Swardt, E. (2005). Towards appropriate methodologies to research interactive learning: Using a design experiment to assess a learning programme for complex thinking. International Journal of Education and Development Using Information and Communication Technology (IJEDICT), 1(2), 105-117.

Boyd, R. (2002). Scientific realism. Stanford Encyclopedia of Philosophy. Retrieved June 10, 2009 from http://plato.stanford.edu/entries/scientific-realism/

Brown, A. L. (1992). Design experiments: Theoretical and methodological challenges in creating complex interventions in classroom settings. The Journal of the Learning Sciences, 2(2), 141178.

Butler, D. M., \& MacGregor, I. D. (2003). GLOBE: Science and education. Journal of Geoscience Education, 51(1), 9-20.

Chalmers, A. F. (1999). What is this thing called science? (3rd ed.). Milton Keynes, UK: Open University Press.

Cobb, P., Confrey, J., diSessa, A., Lehrer, R., \& Schauble, L. (2003). Design experiments in educational research. Educational Researcher, 32(1), 9-13.

Collins, A. (1992). Toward a design science of education. In E. Scanlon \& T. O'Shea (Eds.), New directions in educational technology (pp. 15-22). New York: Springer Verlag.

Collins, A. (1999). The changing infrastructure of education research. In E. Lagemann \& L. Shulman (Eds.), Issues in education research (pp. 289-298). San Francisco: Jossey-Bass.

Collins, A., Joseph, D., \& Bielaczyc, K. (2004). Design research: Theoretical and methodological issues. Journal of the Learning Sciences, 13(1), 15-42.

Culp, K. M., Honey, M., \& Mandinach, E. (2005). A retrospective on twenty years of education technology policy. Journal of Educational Computing Research, 32(3), 279-207.

Davis, B., Sumara, D., \& Luce-Kapler, R. (2000). Engaging minds: Learning and teaching in a complex world. Mahway, NJ: Lawrence Erlbaum Associates.

Dede, C. (2004). If design-based research is the answer, what is the question? A commentary on Collins, Joseph, and Bielaczyc; diSessa and Cobb; and Fishman, Marx, Blumenthal, Krajcik, and Soloway in the JLS special Issue on design-based research. The Journal of the Learning Sciences, 13(1), 105-114.

Design Research Collective Team. (2003). Design-based research: An emerging paradigm for educational inquiry. Educational Researcher, 32(1), 5-8.

Diehl, C., Ranney, M., \& Schank, P. (2001). Model-based feedback supports reflective activity in collaborative argumentation. In P. Dillenbourg, A. Eurelings, \& K. Hakkarainen (Eds.), European perspectives on computer-supported collaborative learning (pp. 189-196) [Proceedings of the First European Conference on Computer-Supported Collaborative Learning], Netherlands: Universiteit Maastricht.

Earle, R. S. (2002). The integration of instructional technology into public education: Promises and challenges. Educational Technology Magazine, 42(1), 5-13. 
Feistritzer, C E. (1999). The making of a teacher: Report on teacher preparation in the US. Washington DC: The National Centre for Education Information. Retrieved May 18, 2009 from http://www. ncei. com/MOT/MOT-1. htm

Fishman, B., Marx, R. W., Blumenfeld, P., Krajcik, J., \& Soloway, E. (2004). Creating a framework for research on systemic technology innovations. Journal of Learning Sciences, 13(1), 43-76.

Good, T. L., \& Brophy, J. E. (1990). Educational psychology: A realistic approach (4 ${ }^{\text {th }}$ ed.). White Plains, NY: Longman.

Goodfrey-Smith, P., (2003). An introduction to the philosophy of science: Theory and reality. Chicago: The University of Chicago.

Gordon, J., \& Zemke, R. (2000). The attack on ISD. Training, 37, 43-53.

Gorard, S., Roberts, K., \& Taylor, C. (2004). What kind of creature is a design experiment? British Education Research Journal, 30 (4), 577.

Hargreaves, A. (2003). Teaching in the knowledge society: Education in the age of insecurity. New York: Teachers College Press.

Hempel, C.G., \& Oppenheim, P. (1948). Studies in the logic of explanation. Philosophy of Science, $15,135-175$.

Hickey, T. (2005). History of twentieth-century philosophy of science. Retrieved March 15, 2009, from http:/www.philsci.com/index.html

Jungwirth, E. (1970). An evaluation of the attained development of the intellectual skills needed for 'understanding of the nature of scientific enquiry' by BSCS pupils in Israel. Journal of Research in Science Teaching, 7(2), 141-151.

Kaptelinin, V., \& Nardi, B. (2006). Acting with technology: Activity theory and interaction design. Cambridge, MA: MIT Press.

Kelly, A. E. (2003). Research as design. Educational Researcher, 32(1), 3-4.

Kelly, A. E., \& Lesh, R. A. (Eds.). (2000). Handbook of research design in mathematics and science education. Mahwah, NJ: Lawrence Erlbaum Associates.

Kelly D., \& Tangney B. (2006) Adapting to intelligence profile in an adaptive educational system. Interacting with Computers 18, 385-409.

Koehler, M. J., \& Mishra, P. (2005). What happens when teachers design educational technology? The development of technological pedagogical content knowledge. Journal of Educational Computing Research, 32(2), 131-152.

Kozma, R., \& Wagner, D. (2006). Reaching the most disadvantaged with ICT: What works? In R. Sweet \& D. Wagner (Eds.), ICT in non-formal and adult education: Supporting out-of-school youth and adults (pp. 97-120). Paris: OECD.

Kuhn, T. S. (1970). The structure of scientific revolution. Chicago: University of Chicago.

Kulik, J. A. (1994). Meta-analytic studies of findings on computer-based instruction. In E. L. Baker and H. F. O’Neil, J. (Eds.). Technology Assessment in Education and Training. Hillsdale, NJ: Lawrence Erlbaum.

Lagrange, J. B., Artigue, M., Laborde, C., \& Trouche, L. (2001). A meta study on IC technologies in education: Towards a multidimensional framework to tackle their integration. Retrieved $\begin{array}{llll}\text { October } & 10, & 2009 & \text { from }\end{array}$ http://didmat.dima.unige.it/miur/miur_dima/G/STORIA_DI_UNA_RICERCA/LAGRANGE. PDF

Lehtelä, P. (2001). Role-playing, Conceptual Change, and the Learning Process: A Case Study of 7th Grade Pupils. In H. Behrendt et al. (Eds.), Research in Science Education - Past, Present, and Future (pp. 211-216). Netherlands: Kluwer Academic Publishers.

Linn, M. (1992). The computer as learning partner: Can computer tools teach science? In K. Sheingold, L. G. Roberts, \& S. M. Malcom (Eds.), This year in school science 1991: Technology for teaching and learning (pp. 31-69). Washington, DC: American Association for the Advancement of Science.

Lunenfeld, P. (2003). The design cluster. In B. Laurel (Ed.), Design research: Methods and perspectives (pp. 10-15). Cambridge, MA: The MIT Press.

Matthews, M. (1994). Science teaching: The role of history and philosophy of science. New York: Routledge. 
Nason, R., \& Woodruff, E. (2004). Online Collaborative Learning in Mathematics: Some necessary innovations. In T. Roberts (Ed.), Online learning: Theory and practice (pp. 103-131). Hershey, PA: Idea Group.

Negroponte, N., Resnick, M., and Cassell, J. (1997). Creating a learning revolution. Retrieved May 15, 2009, from http://www.unesco.org/education/educprog/lwf/doc/portfolio/opinion8.htm

November, A. (2002). Teaching and learning the structure of information. In A. November, Empowering students with technology (pp. 1-20). Glenview, IL: SkyLight Training and Publishing.

O’Donnell, A. M. (2004). A commentary on design research. Educational Psychologist, 39(4), 255-260.

Ow, J., \& Tan, S. C. (2006). Learning of science in an elementary classroom through knowledge

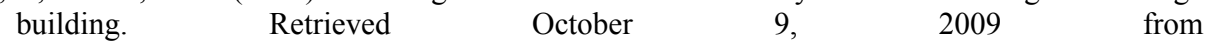
http://iresearch.edumall.sg/iresearch/slot/u110/pubs/lg_sci_thru_kb.pdf

Park, H., Khan, S., \& Petrina, S. (2009). ICT in Science Education: A quasi-experimental study of achievement, attitudes toward science, and career aspirations of Korean middle school students. International Journal of Science Education, 1-20.

Popper, K. R. (1963). Conjectures and refutations: The growth of scientific knowledge. Abingdon: Routledge.

Reeves, T. C. (1995). Questioning the questions of instructional technology research. Paper presented at the National Convention of the Association for Educational Communications and Technology (AECT), Anaheim, CA. February 8-12. Retrieved December 20, 2007, from http://www.gsu.edu/ wwwitr/docs/dean/index.html

Reeves, T. C. (2000). Enhancing the worth of instructional technology research through "design experiments" and other development research strategies. Paper presented at Annual Meeting of the American Educational Research Association, New Orleans, LA. Retrieved December 20, 2007, from http://it.coe.uga.edu/ treeves/AERA2000Reeves.pdf

Reeves, T. C. (2003). Storm clouds on the digital education horizon. Journal of Computing in Higher Education, 15(1), 3-26.

Roschelle, J. \& Pea, R. (1999). Trajectories from today's WWW to a powerful educational infrastructure. Educational Researcher, 8(5), 22-25.

Roschelle, J. M., Pea, R. D., Hoadley, C. M., Gordin, D. N., \& Means, B. M. (2000). Changing how and what children learn in school with computer-based technologies. The Future of children 10(2), 76-101.

Scardamalia, M. (2002). Collective cognitive responsibility for the advancement of knowledge. In B. Smith (Ed.), Liberal Education in the Knowledge Age (pp. 67-98). Chicago, IL: Open Court.

Schrum, L. \& Glassett, K. (2006, April). Research on educational technology: Challenges to implementation and impact of scientifically based research. Paper presented at the American Educational Research Association Annual Meeting. San Francisco.

Sfard, A. (1998). On two metaphors for learning and the dangers of choosing just one. Educational Researcher, 27(2), 4-13.

Shavelson, R., Philips, D. C., Towne, L., \& Feuer, M, J. (2003). On the science of education design studies. Educational Researcher, 32(1), 25-28.

Siegel, H. (2002). Culture and comparative studies. Science Education, 86(6), 803-820.

Sivin-Kachala, J. (1998). Report on the effectiveness of technology in schools, 1990-1997. Software publisher's association.

Smeets, E. (2005). Does ICT contribute to powerful learning environments in primary education? Computers \& Education, 44, 343-355.

Squire, K. \& Klopfer, E. (2007). Augmented reality simulations on handheld computers. The Journal of the Learning Sciences, 16(3), 371-413.

Thagard, P. (1978). Why astrology is a pseudoscience. In M. Curd \& J. A. Cover (Eds.), Philosophy of science: The central issues (pp. 27-38). New York: Norton.

Vygotsky, L. S. (1978). Mind and society: The development of higher mental processes. Cambridge, MA: Harvard University Press. 
White, B. Y., \& Frederiksen, J. R. (1998). Inquiry, modeling, and metacognition: Making science accessible to all students. Cognition and Instruction, 16(1), 3-118.

Williams, R., II, Chen, M., \& Seaton, J. (2003). Haptics-augmented simple-machine educational tools. Journal of science educational technology, 12(1), 16-27.

Woodruff, E., \& Nirula, L. (2005). Design research in the elementary school classroom. Hershey, PA: Idea Group.

\footnotetext{
Hyeran Park is a PhD candidate at Ontario Institute for Studies in Education, University of Toronto. Her research interests include students' understanding of nature of science, what affects students' understanding of science, and how to integrate ICT into a science classroom.

Zuochen Zhang is an Associate Professor at Faculty of Education, University of Windsor. His research interests include Educational Technology, e-learning, and international education.
} 